\title{
PUSAT PENGEMBANGAN KEPERCAYAAN DIRI
}

\author{
Dessy Andiwijaya ${ }^{1)}$, Franky Liauw ${ }^{2)}$ \\ 1)Program Studi S1 Arsitektur, Fakultas Teknik, Universitas Tarumanagara, dessyandiwijaya@gmail.com \\ ${ }^{2)}$ Program Studi S1 Arsitektur, Fakultas Teknik, Universitas Tarumanagara, frankyl@ft.untar.ac.id
}

\begin{abstract}
Abstrak
Kepercayaan diri merupakan aspek yang sangat penting dalam kehidupan kita. Setiap orang berbeda satu dan lainnya, masing-masing memiliki karakter yang khas melekat pada dirinya. Dari perbedaan itulah, dapat diketahui bahwa terdapat orang yang percaya diri, namun ada pula orang yang kurang percaya diri. Karena dengan kita kurang percaya diri, kita akan melewatkan kesempatan-kesempatan yang ada dalam kehidupan ini, misalnya pekerjaan. Kepercayaan diri juga membuat seseorang bersikap gugup, cemas, sulit untuk berinteraksi sosial dan tidak dapat untuk menemukan konsep diri. Dari hal di atas, seakan-akan kepercayaan diri merupakan akar dari kehidupan karena hal ini menentukan pikiran dan aktivitas yang akan kita lakukan seharihari. Kepercayaan diri diperngaruhi oleh faktor internal dan faktor eksternal. Faktor eksternal yaitu lingkungan keluarga, lingkungan teman dan pekerjaan. Kepercayaan diri dan karakter seseorang mempengaruhi segala aspek kehidupan seseorang, misalnya finansial, pekerjaan, kehidupan sosial dan lain-lain. Faktor internal dari kurangnya kepercayaan diri yaitu konsep diri, harga diri, dan pengalaman hidup. Rasa percaya diri(confidence) menentukan bagaimana seseorang akan menilai dan menghargai dirinya pribadi. Kepercayaan diri merupakan keyakinan akan kemampuan diri sendiri untuk mencapai suatu hal dan dapat menerima kekurangan diri sehingga menjadikan kekurangan tersebut menjadi kekuatan dalam diri kita. Sedangkan menurut Hurlocks, Confidence(kepercayaan diri) merupakan sikap pada diri seseorang yang dapat/ bisa menerima kenyataan, mengembangkan kesadaran diri, berpikir positif, memiliki kemandirian,\& mempunyai kemampuan untuk memiliki segala sesuatu yang diinginkan.Untuk mengembangkan kepercayaan diri, kita perlu meningkatkan meningkatkan konsep diri, kemampuan dan interaksi sosial.
\end{abstract}

Kata kunci: kemampuan; kepercayaan diri; konsep diri; pengembangan diri

\section{Abstract}

Self-confidence is a very important aspect of our lives. Everyone is different from one another, each has a unique character attached to him. From that difference, it can be seen that there are people who are confident, but there are also people who lack confidence. Because with us lacking in confidence, we will miss the opportunities that exist in this life, such as work. Self-confidence also makes a person nervous, anxious, difficult to interact socially and unable to find self-concept. From the above, as if self-confidence is the root of life because it determines the thoughts and activities that we will do everyday. Self-confidence is influenced by internal factors and external factors. External factors are family environment, friend environment and work. A person's confidence and character influences all aspects of a person's life, such as finance, work, social life and others. Internal factors of lack of confidence are self-concept, self-esteem, and life experience. Confidence (confidence) determines how a person will judge and respect him personally. Self-confidence is a belief in the ability of yourself to achieve something and can accept self-deficiencies so that these deficiencies become a strength in us. Whereas according to Hurlocks, Confidence (self-confidence) is an attitude in someone who can / can accept reality, develop self-awareness, think positively, have independence, \& have the ability to have everything that is desired. To develop self-confidence, we need to improve self concept, ability and social interaction.

Keywords: ability; confidence; self-concept; self-development

\section{PENDAHULUAN}




\section{Latar Belakang}

Setiap orang berbeda satu dan lainnya, masing-masing memiliki karakter yang khas melekat pada dirinya. Dari perbedaan itulah, dapat diketahui bahwa terdapat orang yang percaya diri, namun ada pula orang yang kurang percaya diri. Rasa percaya diri (confidence) menentukan bagaimana seseorang akan menilai dan menghargai dirinya. Orang yang kurang percaya diri akan terlihat dari sikap dan tindakannya. Ciri-ciri seseorang yang kurang percaya diri adalah mudah cemas, merasa gugup yang berlebihan saat-saat tertentu, merasa selalu memiliki kekurangan fisik maupun non fisik akan dirinya, kurang mengenal potensi akan dirinya, tidak yakin akan kemampuannya, dan cenderung berpikiran negatif. Kepercayaan diri merupakan sikap pada diri seseorang yang dapat menerima kenyataan, mengembangkan kesadaran diri, berpikir positif, memiliki kemandirian,dan mempunyai kemampuan untuk memiliki suatu yang diinginkan (Anthony,1992).

Terdapat 6 kelas sosial menurut Warner, yaitu Lower-lower Class, Upper-Lower Class, LowerMiddle Class, Upper-Middle Class, Lower-Upper Class dan Upper-Upper Class. Masyarakat yang mengalami kurangnya kepercayaan diri bukan hanya dialami oleh kelas sosial bawah, tetapi dialami oleh kelas sosial menengah juga kelas sosial atas. Kepercayaan diri merupakan hal yang sangat penting bagi kehidupan kita dikarenakan oleh kepercayaan diri yang mempengaruhi segala aspek kehidupan misalnya pekerjaan maupun perekonomian. Banyaknya orang yang kurang percaya diri menjadi alasan dan langkah awal dibuatnya proyek ini.

Menurut Hurlocks, perkembangan kepercayaan diri pada masa remaja dipengaruhi oleh pola asuh, penampilan fisik, kematangan usia , hubungan keluarga, jenis kelamin, dan teman. Sedangkan menurut Lauster (2002) terdapat beberapa karakteristik untuk menilai individu yang percaya diri yaitu percaya akan kemampuan diri sendiri, bertindak mandiri, memiliki konsep diri yang positif, berani mengungkapkan pendapat. Sedangkan menurut saya pribadi, untuk mengembangkan kepercayaan diri dengan meningkatkan konsep diri, kemampuan dan interaksi sosial. Konsep diri merupakan pandangan dan sikap individu terhadap diri sendiri.

\section{Identifikasi Masalah}

- Milenial Jakarta yang mengalami kekurangan kepercayaan diri

- Kepercayaan diri yang merupakan aspek yang sangat penting dalam kehidupan,tetapi masih banyak masyarakat Jakarta yang masih kurang percaya diri dilihat dari mereka yang merasa kurangnya kemampuan diri, konsep diri dan kurang dapat berinteraksi sosial.

\section{Rumusan Masalah}

- Faktor apa saja yang menyebabkan seseorang kekurangan kepercayaan diri ?

- Bagaimana cara meningkatkan kepercayaan diri seseorang ?

- Apakah kepribadian dan kelas sosial berhubungan dengan kepercayaan diri seseorang ?

- Program aktivitas apa saja yang dapat membuat seseorang lebih percaya diri ?

\section{Ruang Lingkup Pembahasan}

- Pembahasan faktor yang membuat seseorang kurang percaya diri

- Kepribadian dan kelas Sosial mempengaruhi kepribadian

- Pembasan desain bangunan agar orang dapat lebih percaya diri

Usulan Proyek

Proyek yang diajukan yaitu Confidence Development Centre.

\section{Tujuan dan Sasaran Proyek}

Tujuan Proyek

- Untuk menciptakan suasana bangunan yang dapat meningkatkan kepercayaan diri seseorang

- Untuk menciptakan bangunan yang memiliki program aktivitas yang dapat meningkatkan konsep diri, kemampuan diri, dan kemampuan untuk berinteraksi sosial 


\section{Sasaran Proyek}

Proyek ini ditujukan untuk milenial Jakarta yang kurang percaya diri. Bangunan ini juga menerima individu non milenial lain yang memiliki keinginan untuk lebih percaya diri dari rentang usia 13- 54 tahun (usia produktif)

\section{Visi dan Misi}

Visi: meningkatkan kepercayaan diri masyarakat khususnya di kota Jakarta

Misi:

Masyarakat dapat meningkatkan konsep diri

Masyarakat dapat meningkatkan kemampuan diri dan interaksi sosial

\section{KAJIAN LITERATUR Kepercayaan Diri}

Menurut Hambly (1992), kepercayaan diri diartikan sebagai keyakinan terhadap diri sendiri sehingga mampu menagani segala situasi dengan tenang, kepercayaan diri lebih banyak berkaitan dengan hubungan seseorang dengan orang lain. Tidak merasa inferior di hadapan siapapun dan tidak merasa canggung apabila berhadapan dengan banyak orang. Menurut saya pribadi, kepercayaan diri merupakan keyakinan terhadap kemampuan dan sikap diri sendiri dan dapat mengetahui serta menerima kelemahan diri sendiri dan menjadikan kelemahan menjadi kekuatan yang ada dalam diri.

Sementara itu, ciri-ciri orang yang kurang percaya diri, antara lain:

- Takut untuk berinteraksi sosial

- Merasa selalu ada kekurangan yaitu kemampuan maupun fisik dari dalam diri

- Merasa ragu-ragu untuk melakukan sesuatu

- Tidak memiliki konsep diri Faktor yang mempengaruhi kepercayaan diri, antara lain:

Faktor internal, terdiri dari:

- Konsep diri

- Harga diri

- Kondisi fisik

- Pengalaman hidup

Faktor ekternal, terdiri dari: pekerjaan

Cara meningkatkan kepercayaan diri, antara lain:

- Meningkatkan konsep diri

- Konsep diri merupakan pandangan dan sifat individu terhadap diri sendiri

- Meningkatkan kemampuan untuk berinteraksi sosial

- Meningkatkan kemampuan diri

\section{Metode}

Metode yang digunakan dalam perancangan adalah pendekatan naratif., diawali dengan test personality. Test Personality ini berdasar pada Big 5 personalities traits di mana terdapat tipe-tipe orang yang dari yang selalu waspada dan takut diharapkan menjadi lebih terbuka kepada pengalaman-pengalaman baru, orang yang ceroboh dan tidak peduli menjadi lebih rapi dan efisien, orang yang bersemangat dengan orang yang kurang bersemangat untuk melakukan sesuatu hal, orang yang mudah diajak berkompromi dengan orang yang selalu mengajak rebut, orang yang gugup dan merasa insecure menjadi seseorang yang confident.

Setelah melewati test personality ini pengunjung tersebut akan mengetahui kekurangan apa dalam dirinya dan akan didiskusikan di ruang konsultasi. Di mana di sana terdapat masukan-masukan untuk mengembangkan diri. Penerimaan diri juga sangat penting dalam proses mengembangkan kepercayaan diri. Penerimaan diri di sini dengan cara meningkatkan kesadaran diri dengan 
menerima kekurangan yang dimiliki diri sendiri. Di bangunan ini juga menggabungkan status social di mana seseorang yang memiliki status social rendah / kurang mampu dapat berinteraksi dengan status social tinggi / elite. Hal ini juga berhubungan dengan beberapa spot bangunan yang dibuat terbuka dan dipilihnya material kaca untuk membuat bangunan terlihat terbuka secara visual. Setelah melalui penerimaan diri, akan dilanjutkan dengan pengembangan diri dalam bentuk ilmu, karakter dan keahlian. Setiap step yang dilalui akan dirasakan oleh pengguna untuk meningkatkan kepercayaan diri mereka.

\section{DISKUSI DAN HASIL}

\section{Lokasi}
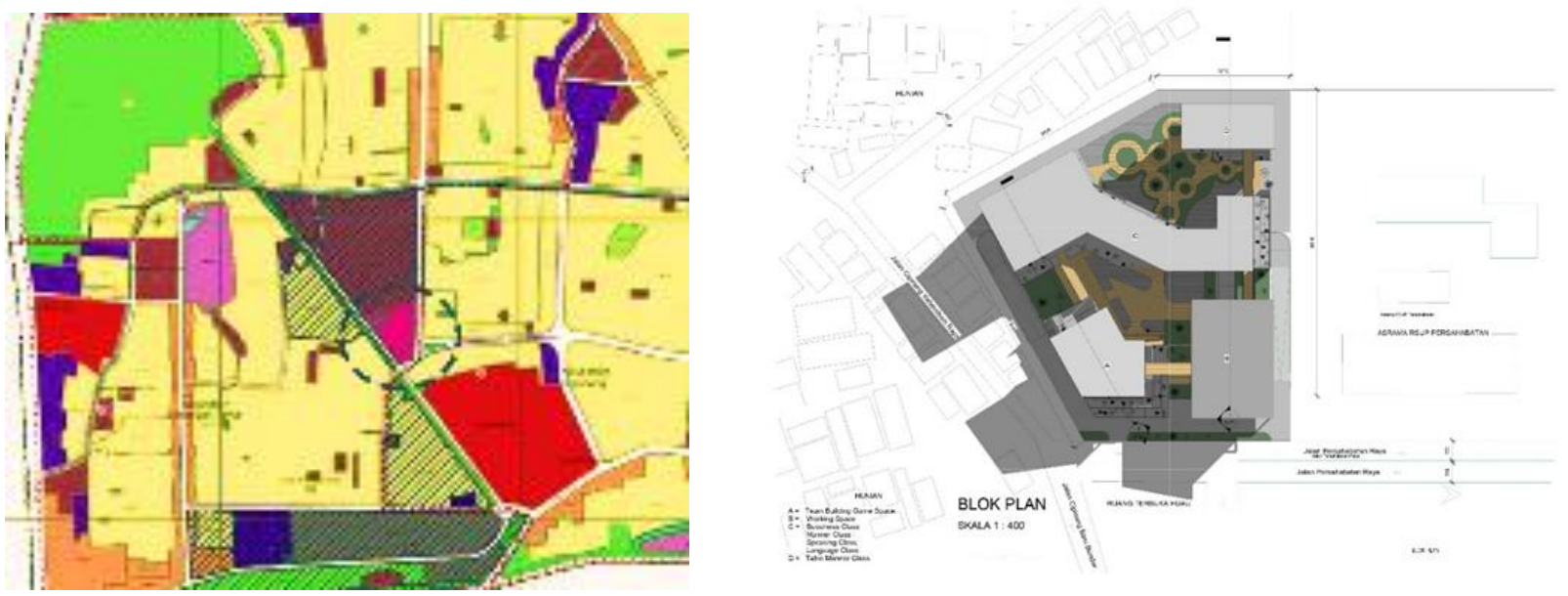

Gambar 1(a). Peruntukkan Lahan; 1(b). Block Plan

Sumber : Sumber : https://dcktrp.jakarta.go.id/beranda/pz-timur.htm/

Peruntukkan lahan untuk kepentingan sosial dan budaya. Lahan berlokasi di Jl.Persahabatan Raya, RT.16/RW.13, Cipinang, Kec. Pulo Gadung, Kota Jakarta Timur, dengan Luas Lahan : $6.900 \mathrm{~m}^{2}$; KDB : $6900 \times 40 \%=2760 \mathrm{~m}^{2} ; \mathrm{KLB}: 1.6 \times 6900=11.040 \mathrm{~m}^{2} ; \mathrm{KB}=4 ; \mathrm{KDH}=6900 \times 30 \%=2070 \mathrm{~m}^{2} ;$ dan GSB : 5 meter

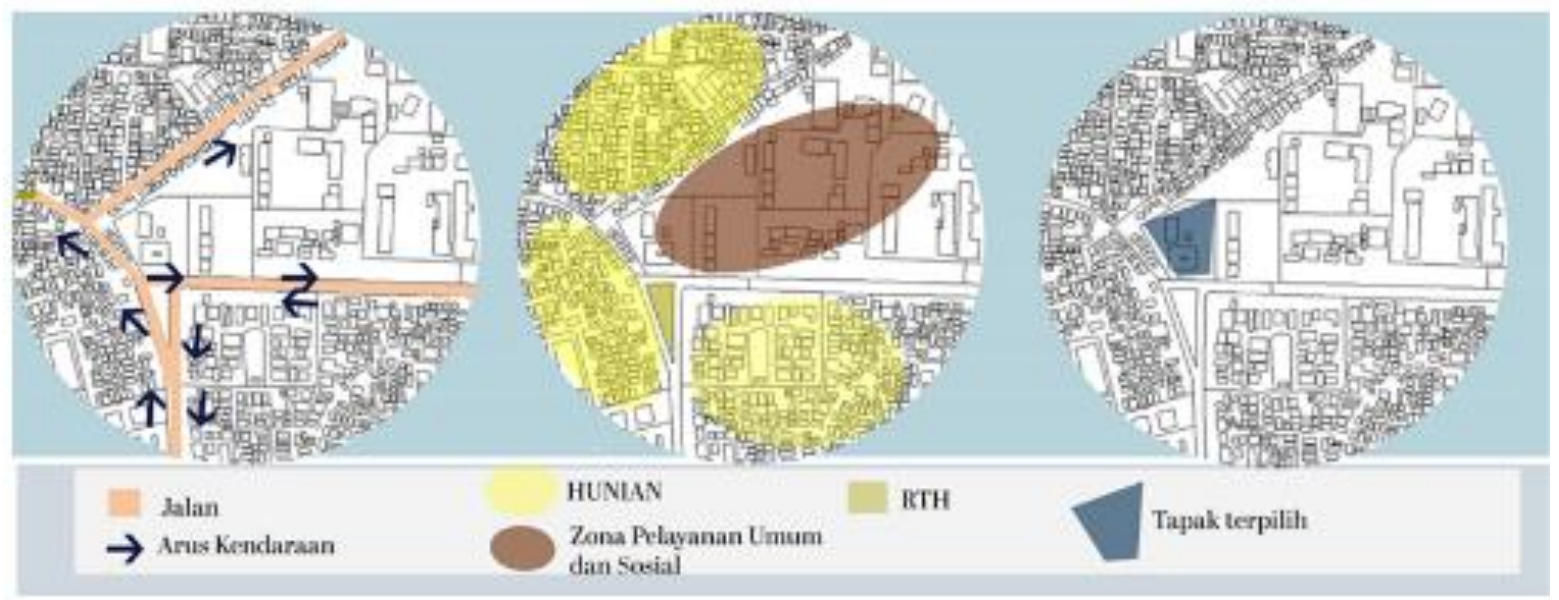

Gambar 2. Analisis Lokasi

Sumber: Penulis, 2019

\section{Program Kegiatan}


Tabel 1. Program Ruang

\begin{tabular}{|c|c|c|c|c|c|}
\hline Level & Name & Area & Leval & Name & Area \\
\hline \multirow{2}{*}{$\begin{array}{l}\text { Semibase } \\
\text { ment }\end{array}$} & \multirow{2}{*}{ Area Parkir } & \multirow{2}{*}{$3361 \mathrm{~m}^{2}$} & \multirow{4}{*}{$\begin{array}{l}\text { Level } 3 \\
\text { Level } 3\end{array}$} & \multirow{4}{*}{$\begin{array}{l}\text { Teacher's room } \\
\text { Public } \\
\text { Speaking Class } \\
\text { Teens }\end{array}$} & \multirow{4}{*}{$\begin{array}{l}100 \mathrm{~m}^{2} \\
181 \mathrm{~m}^{2}\end{array}$} \\
\hline & & & & & \\
\hline Site Plan & Amphiteater & $897 \mathrm{~m}^{2}$ & & & \\
\hline \multirow[t]{2}{*}{ Site Plan } & \multirow{2}{*}{$\begin{array}{l}\text { Walking } \\
\text { Meditation } \\
\text { Space }\end{array}$} & \multirow{2}{*}{$1232 m^{2}$} & & & \\
\hline & & & Level 3 & $\begin{array}{l}\text { Meditation } \\
\text { room }\end{array}$ & $74 \mathrm{~m}^{2}$ \\
\hline \multirow[t]{2}{*}{ Site Plan } & \multirow{2}{*}{$\begin{array}{l}\text { Ruang Test } \\
\text { Personality for } \\
\text { Teens }\end{array}$} & \multirow[t]{2}{*}{$128 \mathrm{~m}^{2}$} & Level 3 & $\begin{array}{l}\text { Parenting } \\
\text { Class }\end{array}$ & $76 \mathrm{~m}^{2}$ \\
\hline & & & \multirow[t]{2}{*}{ Level 3} & \multirow{2}{*}{$\begin{array}{l}\text { Discussion } \\
\text { Space }\end{array}$} & \multirow[t]{2}{*}{$404 \mathrm{~m}^{2}$} \\
\hline Site Plan & Food Court & $533 \mathrm{~m}^{2}$ & & & \\
\hline Site Plan & Lobby & $305 \mathrm{~m}^{2}$ & \multirow[t]{2}{*}{ Level 4} & \multirow{2}{*}{$\begin{array}{l}\text { Bussiness } \\
\text { Class }\end{array}$} & \multirow[t]{2}{*}{$100 \mathrm{~m}^{2}$} \\
\hline Sita Plan & Exhibition room & $283 \mathrm{~m}^{2}$ & & & \\
\hline Site Plan & $\begin{array}{l}\text { Ruang } \\
\text { Konsultasi }\end{array}$ & $72 \mathrm{~m}^{2}$ & Level 4 & $\begin{array}{l}\text { Language } \\
\text { Class }\end{array}$ & $61 \mathrm{~m}^{2}$ \\
\hline \multirow[t]{2}{*}{ Site Plan } & \multirow{2}{*}{$\begin{array}{l}\text { Ruang Test } \\
\text { Personality for } \\
\text { Adult }\end{array}$} & \multirow[t]{2}{*}{$101 \mathrm{~m}^{2}$} & Level 4 & Manner Class & $68 m^{2}$ \\
\hline & & & \multirow[t]{2}{*}{ Level 4} & \multirow{2}{*}{$\begin{array}{l}\text { Public } \\
\text { Speaking Class } \\
\text { for Adult }\end{array}$} & \multirow[t]{2}{*}{$132 \mathrm{~m}^{2}$} \\
\hline Level 2 & Perform Space & $149 \mathrm{~m}^{2}$ & & & \\
\hline Level 2 & $\begin{array}{l}\text { Dressing Class } \\
\text { for Man }\end{array}$ & $94 \mathrm{~m}^{2}$ & Level 4 & $\begin{array}{l}\text { Table Manner } \\
\text { Class }\end{array}$ & $102 \mathrm{~m}^{2}$ \\
\hline Level 2 & $\begin{array}{l}\text { Dressing Class } \\
\text { for Woman }\end{array}$ & $82 m^{2}$ & Level 4 & $\begin{array}{l}\text { Discussion } \\
\text { Space }\end{array}$ & $481 \mathrm{~m}^{2}$ \\
\hline Level 2 & Store & $33 m^{2}$ & Level 4 & Team Building & $340 \mathrm{~m}^{2}$ \\
\hline \multirow[t]{2}{*}{ Level 2} & Mindfulness & \multirow[t]{2}{*}{$37 \mathrm{~m}^{2}$} & & Game Space & \\
\hline & Meditation & & \multirow[t]{2}{*}{ Level 4} & \multirow{2}{*}{$\begin{array}{l}\text { Ruang } \\
\text { Konsultasi }\end{array}$} & \multirow[t]{2}{*}{$75 \mathrm{~m}^{2}$} \\
\hline Level 2 & Meditation & $54 \mathrm{~m}^{2}$ & & & \\
\hline & room & & & & \\
\hline Level 2 & $\begin{array}{l}\text { Watching } \\
\text { Video Space }\end{array}$ & $167 \mathrm{~m}^{2}$ & & & \\
\hline Level 2 & Cafe & $167 \mathrm{~m}^{2}$ & & & \\
\hline Level 2 & Reading Space & $617 \mathrm{~m}^{2}$ & & & \\
\hline Level 2 & $\begin{array}{l}\text { Posture Class } \\
\text { for Man }\end{array}$ & $100 \mathrm{~mm}^{2}$ & & & \\
\hline Level 2 & $\begin{array}{l}\text { Posture Class } \\
\text { for Woman }\end{array}$ & $98 \mathrm{~m}^{2}$ & & & \\
\hline Level 2 & $\begin{array}{l}\text { Discussion } \\
\text { Ouddoor Space }\end{array}$ & $137 \mathrm{~m}^{2}$ & & & \\
\hline Level 3 & $\begin{array}{l}\text { Posture Class } \\
\text { Teens }\end{array}$ & $92 \mathrm{~m}^{2}$ & & & \\
\hline Level 3 & $\begin{array}{l}\text { Dressing Class } \\
\text { Teens }\end{array}$ & $72 \mathrm{~m}^{2}$ & & & \\
\hline Level 3 & $\begin{array}{l}\text { Manner Class } \\
\text { Teens }\end{array}$ & $65 \mathrm{~m}^{2}$ & & & \\
\hline Level 3 & $\begin{array}{l}\text { language Class } \\
\text { Teens }\end{array}$ & $72 m^{2}$ & & & \\
\hline
\end{tabular}

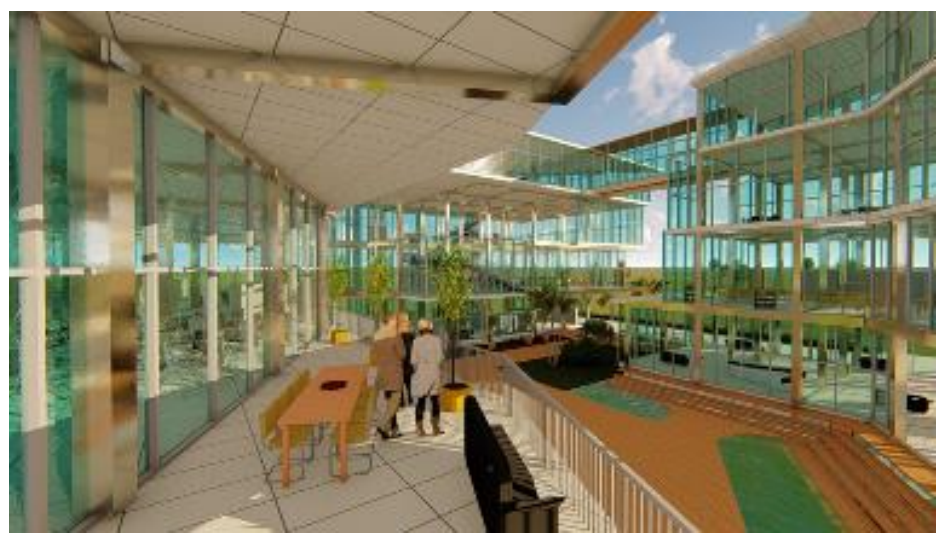

Gambar 4. Perspektif

Sumber: Penulis, 2019

\section{Konsep dan Bentuk rancangan}


Bangunan Confidence Development Centre ini merupakan bangunan untuk mengembangkan kepercayaan. Arti dari kepercayaan diri sendiri adalah sikap pada diri seseorang agar dapat menerima dirinya sendiri, memiliki kesadaran diri dan kemampuan untuk melakukan segala sesuatu yang diinginkan. Pemilihan proyek ini karena confidence/kepercayaan diri yang mempengaruhi segala aspek kehidupan. Contohnya takut untuk memulai suatu kegiatan dan sering berfikir negatif.

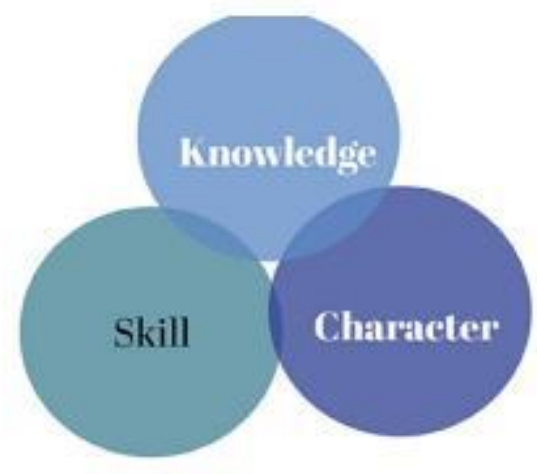

Gambar 5. Skill, Knowledge, Character

Sumber: Penulis, 2019

Bangunan ini menerapkan untuk meningkatkan ilmu, karakter, dan keahlian untuk dapat mengembangkan confidence diri seseorang. Bangunan ini juga menggabungkan character(karakter), skill (keahlian) dan knowledge (ilmu) menjadi program-program yang ada. Program-program ini diperuntukkan bagi usia 13 hingga 54 tahun(usia produktif). Kepercayaan diri dapat dibangun mengembangkan keahlian,ilmu dan karakter. Bangunan ini menggabungkan antara pengajaran ilmu, keahlian, dan karakter untuk memberikan kesempatan kepada seseorang untuk dapat lebih percaya diri. Program-program yang ada dibangunan ini bertujuan agar seseorang dapat menjadi percaya diri yaitu dengan meningkatkan kesadaran, keingintahuan, keberanian, ketahanan, etika dan kepemimpinan.

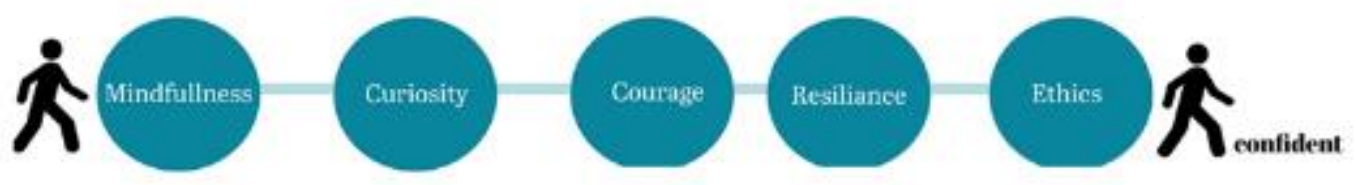

Gambar 6. Tahapan Confidence

Sumber: Penulis, 2019

Menurut Warner terdapat 6 kelas sosial yaitu lower-lower class, upper lower class, upper-middle class, lower-middle class, upper-upper class, lower- upper class. 5 tipe sosial dari upper lower class hingga upper-upper class akan digabungkan di bangunan ini. Dimana di bangunan ini tidak mengenal status social dan mereka diberikan kesempatan untuk saling berinteraksi dan mengembangkan diri mereka. Di bangunan ini akan menggunakan subsidi silang agar masyarakat kurang mampu / UpperLower Class tetap dapat bergabung untuk melatih karakter dan kepercayaan diri sama dengan masyarakat ekonomi atas /upper-uper class. 


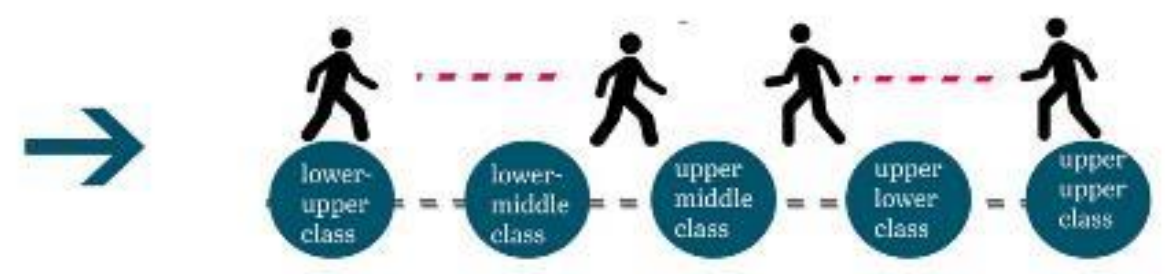

Gambar 7. Kelas Sosial

Sumber: Penulis, 2019

Bangunan dibuat dengan material kaca berawal dari kebutuhan seseorang yang kurang percaya diri dan keinginan agar seseorang dapat bersikap lebih terbuka dan saling berinteraksi.

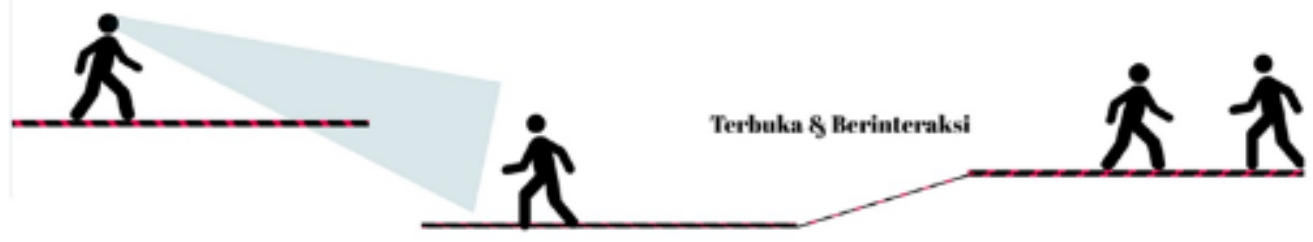

Gambar 8. Interaksi

Sumber: Penulis, 2019

Konsep dari bangunan ini adalah keterbukaan dan tidak ada batas dari segi kelas sosial. Ini dimaksudkan agar segi masyarakat kurang mampu hingga masyarakat ekonomi atas agar dapat bergabung saat melatih karakter dalam 1 lingkungan dan dapat berkembang bersama menjadi individu yang lebih percaya diri dengan cara menerima kekurangan diri sendiri dan kelebihan orang lain. Itu adalah hal dasar untuk mencapai kepercayaan diri yaitu dengan dapat menerima diri sendiri terlebih dahulu. Material kaca yang digunakan pada bangunan ini bertujuan agar bangunan terlihat lebih terbuka secara visual .

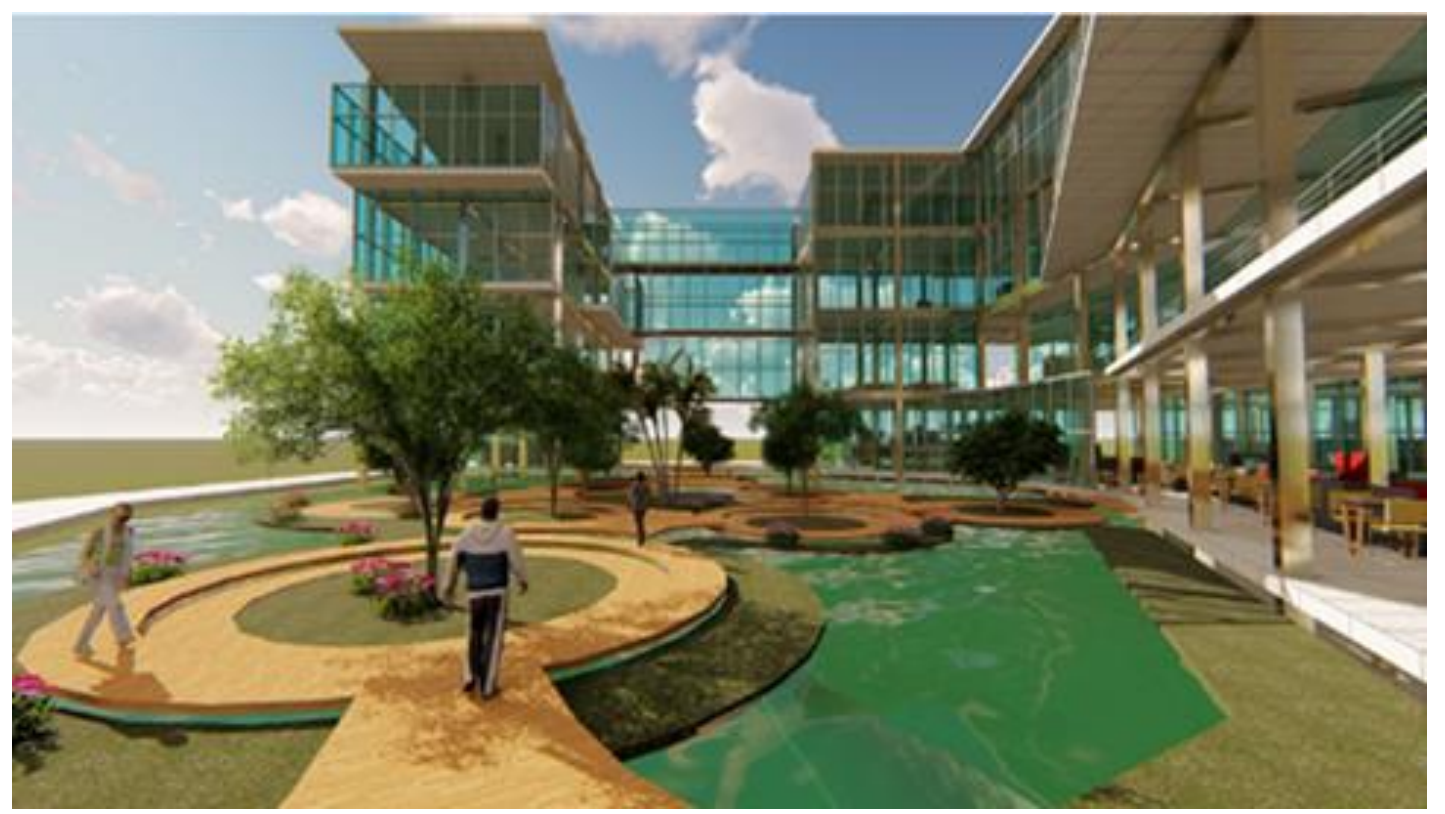

Gambar 9. Perspektif

Sumber: Penulis, 2019 

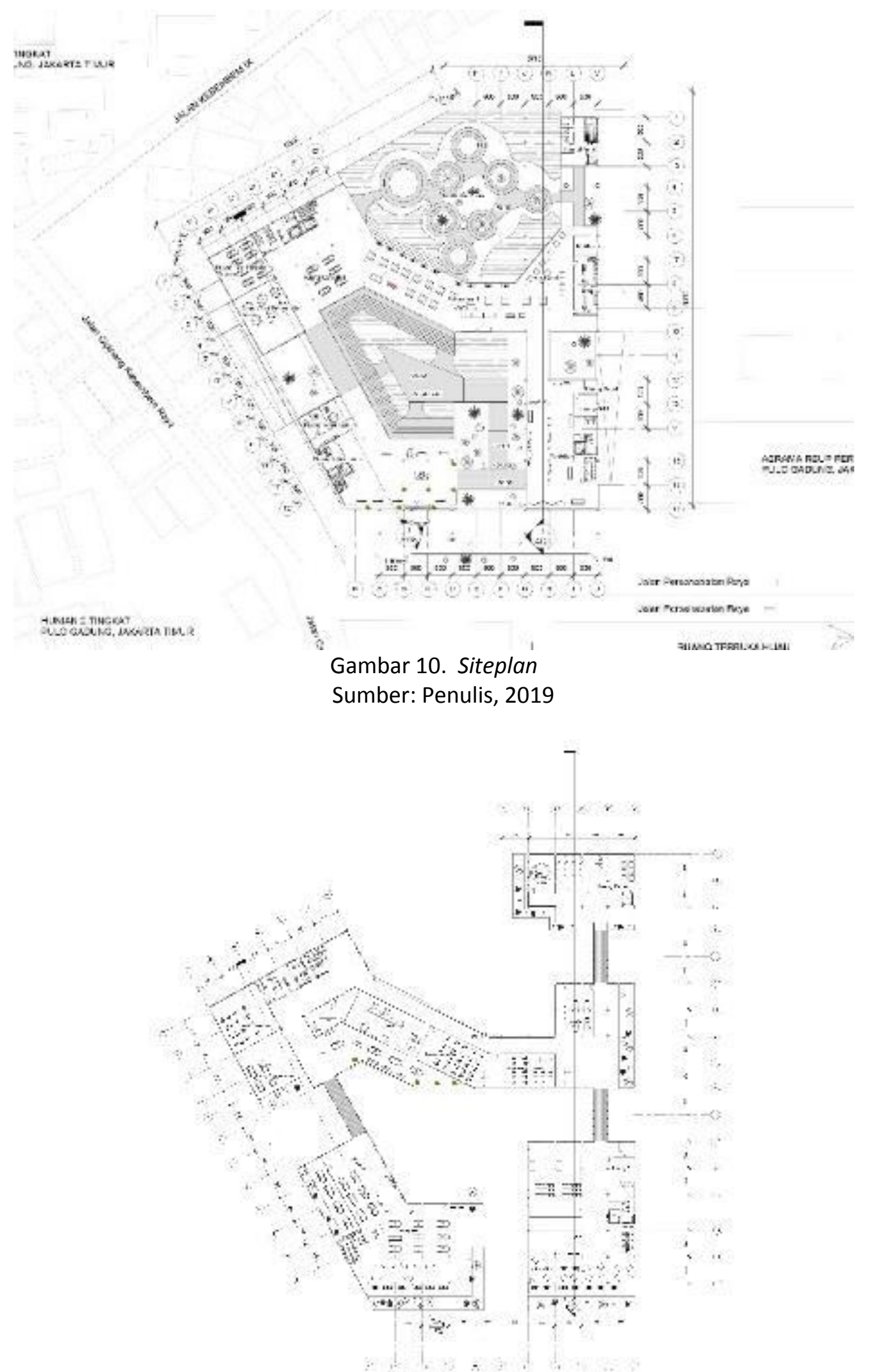

Gambar 11. Denah Lantai 2

Sumber: Penulis, 2019 


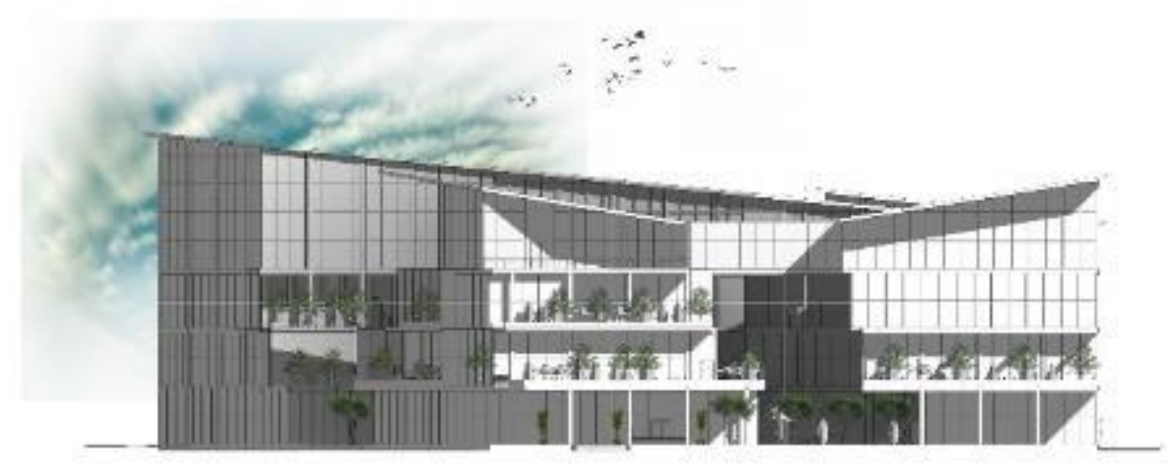

Gambar 12. Tampak Depan

Sumber: Penulis, 2019

\section{Kesimpulan dan Saran}

Masyarakat perlu untuk memiliki rasa kepercayaan diri agar dapat mencapai segala sesuatu yang diinginkan, misalnya kesuksesan dan pekerjaan yang baik. Apabila masyarakat mengalami kekurangan kepercayaan diri. Proyek ini dan program yang ada sangat cocok untuk meningkatkan hal tersebut. Karena proyek ini berdasar untuk meningkatkan kemampuan, konsep diri dan kemampuan interaksi sosial seseorang.

\section{Referensi}

Alvara Research Center. (2015). "The Potraits of Urban Moslem: Gairah Religiusitas Masyarakat Kota".

Anthony, R. (1992). Rahasia Membangun Kepercayaan Diri (terjemahan Rita Wityadi). Jakarta : Binarupa Aksara.

Character Education for 21th Century . 27 Februari 2015. Diakses 20 juni 2019. https://curriculumredesign.org/wp-content/uploads/CCR-

Hambly, K. (1992). Psikologi populer: Bagaimana meningkatkan rasa percaya diri (Terjemahan FX. Budiyanto) Jakarta: Arcan.

Hurlock, E.B.(1997). Psikologi Perkembangan. Jakarta : Erlangga.

Lauster, P. (2005). Tes Kepribadian. Jakarta: Bumi Aksara. 
